\title{
The influence of digitisation and timing errors on the estimation of tidal components at Split (Adriatic Sea)
}

\author{
I. Vilibić \\ Institute of Oceanography and Fisheries, Šetalište I. Meštrovića 63, 21000 Split, Croatia \\ Received: 24 October 2005 - Revised: 29 March 2006 - Accepted: 6 April 2006 - Published: 3 July 2006
}

\begin{abstract}
The paper comprises the calculations of amplitudes and phases of tidal harmonic constituents, performed on hourly sea level data recorded at the Split tide gauge in the period 1957-2001. Interannual changes in all constituents have been detected, stronger in phases than in amplitudes. For example, the estimated change in $\mathrm{M}_{2}$ amplitude and phase is $22 \%(1.31 \mathrm{~cm})$ and $24.9^{\circ}$ between the $1962-$ 1978 and 1957-1961 periods, respectively. Some of the differences are generated artificially throughout the measurements (clock errors, positioning and stretching of a chart) and within the digitising procedure, rather than by natural processes and changes (e.g. changes in mean sea level). This is the reason why the $\mathrm{M}_{2}$ and $\mathrm{K}_{1}$ amplitudes were recomputed with 3-4 mm larger values using newer software, thereby decreasing their standard deviation by $60-70 \%$ in the $1986-$ 1995 period. Artificial errors may be reduced by the upgrading of digitising software; however, most of the errors still remain in the series. These errors may have repercussions when trying to explain some unusual findings: the energy of de-tided sea level series at the $\mathrm{M}_{2}$ tidal period $(12.4 \mathrm{~h}$ ) has been assumed previously to be a result of nonlinear coupling, but it may be caused, at least partly, by timing errors in the time series.
\end{abstract}

Keywords. Oceanography: Physical (Surface waves and tides; Instruments and techniques; General or miscellaneous)

\section{Introduction}

The safety of navigation on the sea, in particular when manoeuvring within and off a harbour, is largely dependent on the magnitude of the surface waves, currents and particularly of the sea level height in the area. Therefore, a lot of effort

Correspondence to: I. Vilibić

(vilibic@izor.hr) have been put into the operational hindcasting/forecasting of various oceanographic parameters (e.g. Prandle, 2000), especially in large high-tidal basins and oceans, where sea level changes can easily reach $10 \mathrm{~m}$ (Pugh, 1987; Chapalain and Thais, 2000). The largest amount of sea-level energy usually comes from the tides, and the determination of tidal constituents and tidal modelling is therefore essential.

The Adriatic Sea is a semi-enclosed, low-tidal basin, with a tidal signal ranging from 30 to $120 \mathrm{~cm}$. Nevertheless, storm surges and seiches can provoke flooding of lowland areas (Robinson et al., 1972; Raicich et al., 1999), more intense when coupled with spring tides. One of the first calculations of Adriatic harmonic constituents was based on Bakar data measured in 1950 (Kasumović, 1952), extracting 7 significant constituents with amplitudes higher than $1 \mathrm{~cm}$. Polli (1960) performed a comprehensive tidal analysis (29 stations) and plotted amplitudes and phases for the whole Adriatic, but using rather old data collected at the beginning of the 20th century. More intense sea level measurements in the Adriatic started in 1955/56, and harmonic constants for 6 ports were computed by Šigud (1973). These constants are still in use for tidal predictions along the eastern Adriatic coast, but they are based on the data obtained from digitized chart records. Therefore, they are largely dependent on the accuracy of the measurements, both in time and in height. The problem seems to arise from temporal errors, as the vertical shift and tide gauge constant have been controlled regularly every year. In particular, time drifts and shifts can occur often in chart-recorded data (UNESCO, 1985), or even be artificially created during the digitising process.

Therefore, this work will be oriented towards the analysis of sea level data collected in the 1957-2001 period at a single Split tide gauge $\left(\mathrm{LAT}=43^{\circ} 30^{\prime} \mathrm{N}, \mathrm{LON}=16^{\circ} 26^{\prime} \mathrm{E}\right)$, in order to check the quality of the data through the estimates of temporal characteristics of the harmonic constituents. The analysis will be performed using the TASK package (Tidal Analysis Software Kit) developed at Proudman Oceanographic

Published by Copernicus GmbH on behalf of the European Geosciences Union. 

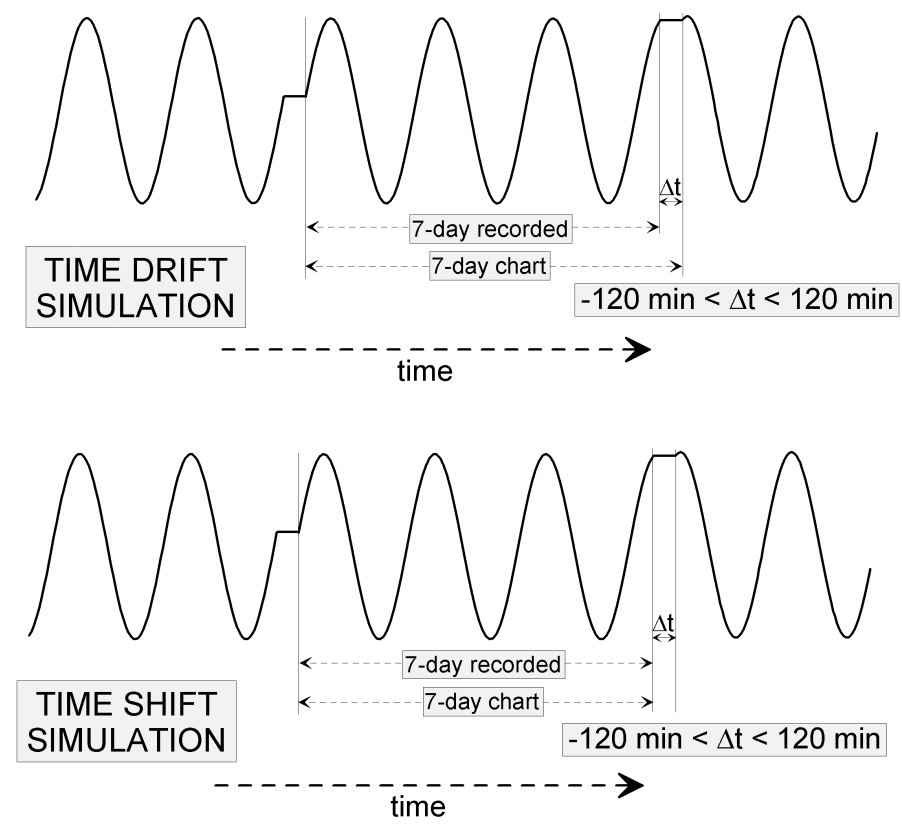

Fig. 1. Scheme of time drift and time shift simulations.

Laboratory, United Kingdom (Bell et al., 2000). A few questions will be addressed and hopefully answered in the paper: How much do computed tides vary in time? Are the changes in tidal amplitudes and phases driven by physical processes or they are artificially induced throughout the measurements and digitising procedure, and (iii) are artificial errors predominant the result of the measurements or of the digitising process? The latter question will include the findings achieved through simulations of time drifts and shifts in the series, both being documented by the tide gauge operators, which will help in answering of the last two questions.

\section{Material and methods}

Tide gauge at Split was reinstalled in 1954 (the first installation was in 1929), by putting a float-type chart recording device into the stilling well. Two years later, the instrument was replaced with a more precise OTT device, enabling the accuracy in sea level height to be smaller than $1 \mathrm{~cm}$. This device is still operational, although it has been upgraded with a high-precision shaft encoder in 2003. The charts have been changed weekly, and digitised on a monthly basis, in order to obtain hourly sea level values and high/low waters. The most common errors in the system reported by the operators were generated by the clock errors (drift in time), wrong positioning of the pen and the broad trace of the pen line when replacing charts (shift in time), and by the elongation of the charts due to different atmospheric conditions (temperature, air humidity) in the tide gauge location, compared to the central storeroom (drift in time).
The digitising of the charts has been performed using two different software packages: (1) the charts from 1978 to 2001 were digitised on an older VAX system, with old FORTRAN software which did not allow one to control and change the digitised values during the digitising process, and therefore the data is supposed to be more prone to digitising errors, and (2) the charts older than 1978 were digitised recently using a PC-based package, which consists of an AutoCAD digitising package, a dxf-xyz conversion program and a FORTRANbased program which calculates the same parameters (hourly values, high/low data) and produces the same data files as the older package. The resolution of both packages is on a 1-cm level, keeping the original accuracy of the measurements in the sea level data. The latter package allows for direct changes of digitised curves if necessary, and therefore it is expected to result in more accurate data than the older one. Apart from measurement errors both drifting and shifting errors have been reported by the operators to occur during digitising, the first being common for the VAX-based software and the second appearing within the AutoCAD-based software.

The calculation of harmonic constants was performed on annual data files, as it is necessary to have a sufficient length of time series to produce the correct amplitudes and phases of the harmonic constituents (Bell et al., 2000). Seven significant constituents were incorporated into analysis performed by TASK package (Bell et al., 2000), namely semidiurnal $\mathrm{M}_{2}, \mathrm{~S}_{2}, \mathrm{~K}_{2}, \mathrm{~N}_{2}$ and diurnal $\mathrm{K}_{1}, \mathrm{O}_{1}$ and $\mathrm{P}_{1}$ tides (Shureman, 1941; Pugh, 1987), which were recognized to be significant in the Adriatic Sea (e.g. Polli, 1960). As year-to-year variations are found both in amplitudes and phases, correlation to 

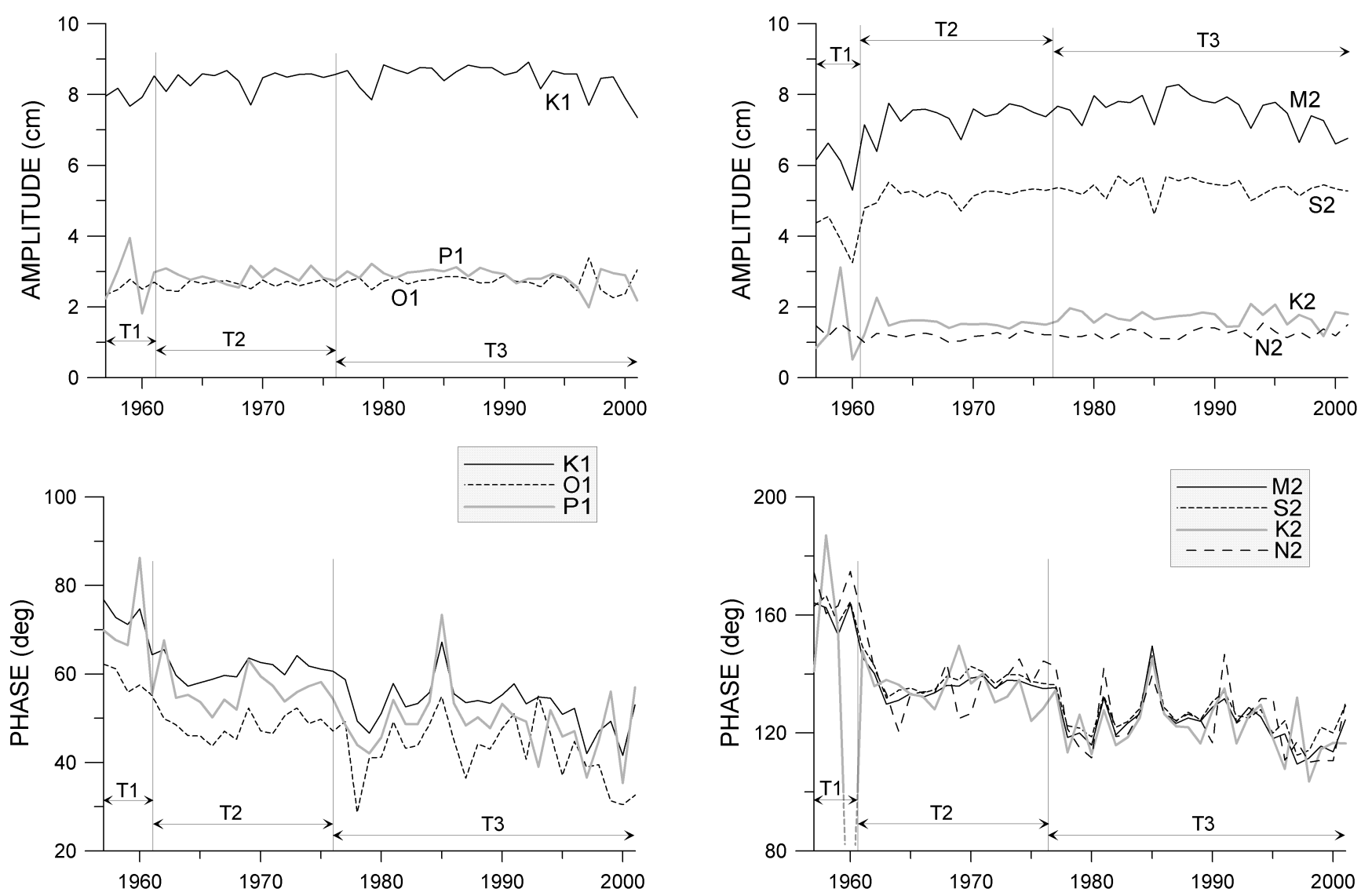

Fig. 2. Annual amplitudes and phases of diurnal constituents calculated for Split in the 1957-2001 period.

the mean sea level (MSL) has been computed as being one of the factors that may change the tides in a coastal region (Lane, 2004). The nodal tide influence (18.6 years, Shureman, 1941) on the diurnal and semidiurnal tides is incorporated in the TASK software through scaling with a nodal factor; therefore, no such oscillations can occur in the tides computed. In addition, no changes in the surrounding topography (dredging, major constructions, etc.) have been reported in the region, which may influence the tides in the Split Harbour.

Apart from natural variations, two idealized simulations were constructed, in order to validate the influence of time drifts and shifts on the characteristics of harmonic constituents, which were reported by the tide gauge operators and data analysis experts (Hydrographic Institute, personal communication). The first run was based on the assumption that each weekly sea level record is stretched or shrunk in time (Fig. 1a), due to clock errors or elongation of a chart due to humidity and temperature changes, with the weekly drift rate varying from -120 to $120 \mathrm{~min}(120 \mathrm{~min}$ is about $8 \mathrm{~mm}$ on a $70-\mathrm{cm}$ weekly chart). The second run was carried out assuming that the clock time was correct, but with an offset (shift) between the weekly records from -120 to

Fig. 3. Annual amplitudes and phases of semidiurnal constituents calculated for Split in 1957-2001 period.

$120 \mathrm{~min}$, due to the wrong positioning of the pen on a chart or due to the errors in digitising of the charts (Fig. 1b). Therefore, the cumulative timing error due to a drift may be up to $\pm 480 \mathrm{~min}$ in a month. Both artificial records were put in the right position in time every 4 weeks (one month), in order to simulate the digitising process which had been done on a monthly basis. As a result, annual synthetic sea level series were constructed, serving as input to the harmonic analysis. Such a procedure resulted in changes in amplitude and phase of the harmonic constituents due to the time drift and shift, compared to the "regular" time series (no shift and drift), and therefore it will be useful within the error analysis of the measured sea level series.

\section{Results}

\subsection{Data analysis}

Figures 2 and 3 show the time series of annual amplitudes and phases of all harmonic constituents, calculated at Split, for the period 1957-2001. The series are split into three subseries: T1 stands for the records where the changes to the 

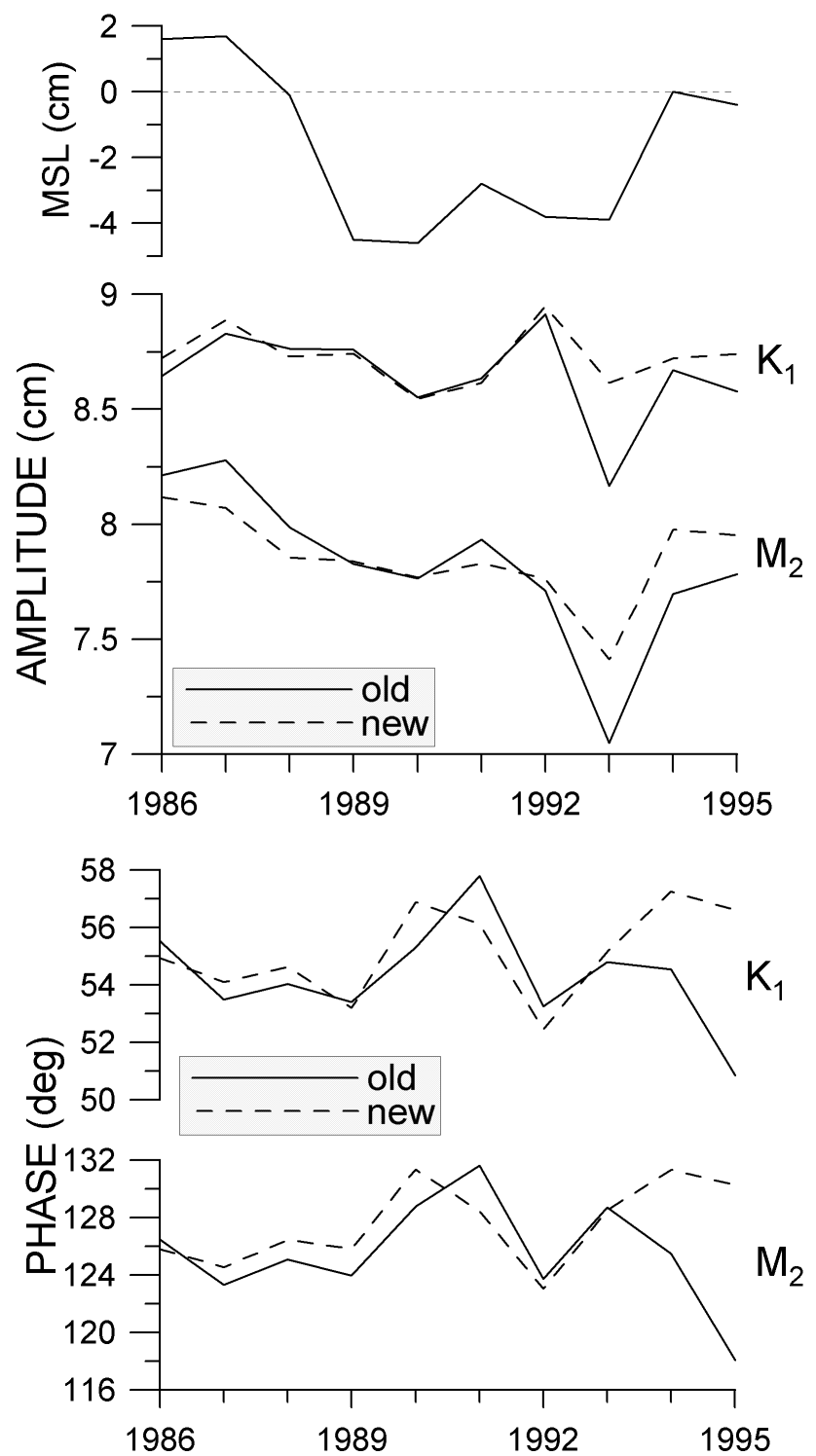

Fig. 4. Mean sea level (MSL) and amplitudes and phases of major $\mathrm{M}_{2}$ and $\mathrm{K}_{1}$ tides between 1986 and 1995 , computed on the data obtained by the VAX (old) and the AutoCAD (new) software.

charts were not done at the regular time, and therefore the accuracy of the sea level data in time is lower, while $\mathrm{T} 2$ and $\mathrm{T} 3$ represent periods when the charts were changed regularly and the time positioning of data is more correct. The difference between $\mathrm{T} 2$ and $\mathrm{T} 3$ is in the digitising process; namely, $\mathrm{T} 2$ charts were digitised using recently developed PC-based software (AutoCAD) and the drifts in time are minimized, contrary to the $\mathrm{T} 3$ charts, which were digitised using an older VAX package, thereby being more prone to errors within the digitising process. The average amplitudes and phases, together with standard deviations are listed in Table 1.

The difference between the constants seems to be rather significant. For example, amplitudes are the lowest in the T1 period (except of $\mathrm{N}_{2}$ tide), opposite that of the phases which are commonly the largest in the $\mathrm{T} 1$ period (except of $\mathrm{K}_{2}$ ). Additionally, the T1 period is characterized by the highest standard deviations. Therefore, the data possesses the lowest quality in the T1 period, which is a logical consequence of the irregular changing of a chart and cannot be bridged by digitising, due to a lack of accurate timing information. The amplitudes in the $\mathrm{T} 3$ period are even a bit higher, whereas the phases are lower compared to the T2 period. However, all of the amplitudes seem to be lower than the ones documented by Šigud (1973). The changes in the semidiurnal amplitudes and phases between the periods are at least two times larger than those of the diurnal ones. For example, the change in the $\mathrm{M}_{2}$ amplitude and phase is $22 \%(1.31 \mathrm{~cm})$ and $24.9^{\circ}$ between the $\mathrm{T} 2$ and $\mathrm{T} 1$ periods, respectively, whereas the respective change in the $\mathrm{K}_{1}$ amplitude and phase is $6 \%(0.50 \mathrm{~cm})$ and $12.7^{\circ}$. Therefore, one can suspect that the drift and shift errors occurred at the charts or during the digitising process, as semidiurnal tides are more sensitive to such errors than the diurnal ones, due to their smaller period.

Although the T2 period has lower standard deviations in both amplitudes and phases than the T3 period, the quality of the software packages may be ranked only when analysing the same period by both packages. Therefore, newer AutoCAD-based software has been applied on the 1986-1995 charts, and new tidal amplitudes and phases have been computed (Table 2) and compared to the old ones. First and foremost, new software gives a bit higher amplitudes and lower standard deviations, of which the latter is the proof that the AutoCAD-based software is more accurate and results in better quality sea level data. Also, larger amplitudes mean that less drifting and shifting errors occurred in time, keeping more energy on the tidal frequencies (see next section). Large data errors do not occur constantly; they are focused in some years, such as 1993 , when both $\mathrm{M}_{2}$ and $\mathrm{K}_{1}$ tides were recomputed with a $3-4 \mathrm{~mm}$ larger amplitude (Fig. 4). Similar characteristics may be concluded for the phase behaviour both software packages have the same outcome with correlated changes in the 1986-1993 period, but they give different results in 1994 and 1995 (the respective $\mathrm{M}_{2}$ and $\mathrm{K}_{1}$ phase differences are about $12^{\circ}$ and $6^{\circ}$ in 1995). Obviously, time drifting and shifting during the digitising process are mostly likely responsible.

Even though it may be concluded that the AutoCAD software gives more accurate data, some variations in amplitudes and phases may be found in the T2 period (and in the newly computed values in the 1986-1995 period). They may be a result of inaccuracy and errors in data processing which are still largely present in the AutoCAD software (although being lower than in the VAX software), or may be a result of real tidal changes in the region induced by various dynamical processes (changes in MSL, dredging, building of piers, baroclinic effects, etc.). The changes in the surrounding bathymetry did not occur in the region in the examined period (Hydrographic Institute of the Republic of Croatia, 
Table 1. Average amplitudes and phases, together with standard deviations calculated for T1, T2 and T3 periods. The constituents given by Šigud (1973) are shown, too.

\begin{tabular}{|c|c|c|c|c|c|c|c|c|c|c|c|c|c|c|}
\hline & \multicolumn{2}{|c|}{$\mathrm{M}_{2}$} & \multicolumn{2}{|c|}{$\mathrm{S}_{2}$} & \multicolumn{2}{|c|}{$\mathrm{K}_{2}$} & \multicolumn{2}{|c|}{$\mathrm{N}_{2}$} & \multicolumn{2}{|c|}{$\mathrm{K}_{1}$} & \multicolumn{2}{|c|}{$\mathrm{O}_{1}$} & \multicolumn{2}{|c|}{$P_{1}$} \\
\hline & $\mathrm{H}(\mathrm{cm})$ & $g\left(\left(^{\circ}\right)\right.$ & $\mathrm{H}(\mathrm{cm})$ & $g\left(\left(^{\circ}\right)\right.$ & $\mathrm{H}(\mathrm{cm})$ & $g\left(\left(^{\circ}\right)\right.$ & $\mathrm{H}(\mathrm{cm})$ & $g\left(\left(^{\circ}\right)\right.$ & $\mathrm{H}(\mathrm{cm})$ & $g\left(\left(^{\circ}\right)\right.$ & $\mathrm{H}(\mathrm{cm})$ & $g\left(\left(^{\circ}\right)\right.$ & $\mathrm{H}(\mathrm{cm})$ & $\mathrm{g}\left({ }^{\circ}\right)$ \\
\hline Šigud (1973) & 7.95 & 129.0 & 5.58 & 130.8 & 1.64 & 124.1 & 1.38 & 125.6 & 8.82 & 55.9 & 2.69 & 47.5 & 2.90 & 51.8 \\
\hline T1 period & $6.06 \pm 0.55$ & $161.0 \pm 5.2$ & $4.02 \pm 0.58$ & $162.8 \pm 4.0$ & $1.43 \pm 1.16$ & $127.2 \pm 69.9$ & $1.36 \pm 0.16$ & $168.2 \pm 7.4$ & $7.94 \pm 0.21$ & $73.9 \pm 2.4$ & $2.53 \pm 0.18$ & $59.2 \pm 3.0$ & $2.76 \pm 0.94$ & $72.6 \pm 9.2$ \\
\hline T2 period & $7.37 \pm 0.36$ & $136.1 \pm 3.9$ & $5.17 \pm 0.21$ & $138.3 \pm 4.3$ & $1.55 \pm 0.21$ & $135.6 \pm 6.7$ & $1.18 \pm 0.10$ & $137.0 \pm 9.3$ & $8.44 \pm 0.25$ & $61.2 \pm 2.4$ & $2.64 \pm 0.11$ & $|48.5 \pm 3.0|$ & $2.88 \pm 0.18$ & $56.4 \pm 4.3$ \\
\hline T3 period & $7.56 \pm 0.46$ & $123.6 \pm 8.4$ & $5.37 \pm 0.25$ & $125.7 \pm 7.1$ & $1.72 \pm 0.20$ & $122.0 \pm 9.3$ & $1.26 \pm 0.14$ & $124.2 \pm 10.6$ & $8.47 \pm 0.40$ & $52.8 \pm 5.3$ & $2.73 \pm 0.23$ & $42.6 \pm 7.2$ & $2.86 \pm 0.27$ & $49.0 \pm 7.5$ \\
\hline
\end{tabular}

Table 2. Average amplitudes and phases, together with standard deviations calculated for 1986-1995 by using old VAX and new AutoCADbased software.

\begin{tabular}{|c|c|c|c|c|c|c|c|c|c|c|c|c|c|c|}
\hline & \multicolumn{2}{|c|}{$\mathrm{M}_{2}$} & \multicolumn{2}{|c|}{$\mathrm{S}_{2}$} & \multicolumn{2}{|c|}{$\mathrm{K}_{2}$} & \multicolumn{2}{|c|}{$\mathrm{N}_{2}$} & \multicolumn{2}{|c|}{$\mathrm{K}_{1}$} & \multicolumn{2}{|c|}{$\mathrm{O}_{1}$} & \multicolumn{2}{|c|}{$\mathrm{P}_{1}$} \\
\hline & $\mathrm{H}(\mathrm{cm})$ & $g\left({ }^{\circ}\right)$ & $\mathrm{H}(\mathrm{cm})$ & $g\left({ }^{\circ}\right)$ & $\mathrm{H}(\mathrm{cm})$ & $g\left({ }^{\circ}\right)$ & $\mathrm{H}(\mathrm{cm})$ & $g\left(\left(^{\circ}\right)\right.$ & $\mathrm{H}(\mathrm{cm})$ & $g\left({ }^{\circ}\right)$ & $\mathrm{H}(\mathrm{cm})$ & $g\left({ }^{\circ}\right)$ & $\mathrm{H}(\mathrm{cm})$ & $\mathrm{g}\left({ }^{\circ}\right)$ \\
\hline 1986-1995 old & $7.82 \pm 0.34$ & $125.5 \pm 3.7$ & $5.45 \pm 0.22$ & $126.8 \pm 3.9$ & $1.77 \pm 0.21$ & $124.0 \pm 6.1$ & $1.30 \pm 0.15$ & $127.8 \pm 7.9$ & $8.65 \pm 0.20$ & $54.3 \pm 1.8$ & $2.76 \pm 0.10$ & $44.7 \pm 5.8$ & $2.91 \pm 0.14$ & $48.9 \pm 4.2$ \\
\hline 1986-1995 new & $7.86 \pm 0.20$ & $127.6 \pm 2.9$ & $5.51 \pm 0.15$ & $129.3 \pm 3.2$ & $1.78 \pm 0.16$ & $127.1 \pm 4.6$ & $1.22 \pm 0.13$ & $129.4 \pm 8.8$ & $8.73 \pm 0.12$ & $55.1 \pm 1.6$ & $2.81 \pm 0.11$ & $44.5 \pm 4.1$ & $3.00 \pm 0.22$ & $49.6 \pm 4.0$ \\
\hline
\end{tabular}

private communication). On the other hand, the changes in MSL are correlated with the changes in some tidal amplitudes on the 95\% level (Fig. 5), but not for other amplitudes and not for all of the tidal phases. Furthermore, most of the AutoCAD-computed amplitudes in 1986-1995 are correlated with the VAX-computed amplitudes (Fig. 6), which is predominantly a result of the errors that occurred during the measurements which cannot be improved by the digitising software. Therefore, the lower variance obtained by AutoCAD software is the result of the improvement of the digitising process and the lowering of the artificial errors there. Conclusively, some improvement in sea level data quality can be made by improving the digitising software, but only to the level limited by the errors acquired through the measurement processes which cannot be resolved and corrected during the reanalysis.

\subsection{Time drift and shift simulations}

Simulated changes in constituent amplitudes and phases due to the artificial drift and shift in the time series (see Fig. 1 and Sect. 2) are shown in Fig. 7. One can see that the changes in amplitude are not so pronounced as the changes in phase, both for semidiurnal and diurnal constituents, being almost linearly shifted in the same direction as the constructed time series. If the drift is large enough, semidiurnal amplitudes decrease rather rapidly, for about $4 \%$ for a drift rate of $\pm 120 \mathrm{~min}$. This is equivalent to about $3 \mathrm{~mm}$ for the
$M_{2}$ tide or about $2 \mathrm{~mm}$ for the $\mathrm{S}_{2}$ tide, which is still significantly lower than the standard deviation in all of the examined periods (Tables 1 and 2). The drift impacts tidal phases quite a lot versus the observed variability; this is due to the fact that each sea level chart can be drifted with a different value. The changes in diurnal tides are significantly lower; $\mathrm{K}_{1}$ decreases only $1 \mathrm{~mm}$ if the drift is $120 \mathrm{~min}$. A small exception is the $P_{1}$ tide, which increases in amplitude when the drift rate is negative. Such behaviour is a result of artificial energy transfer from the $\mathrm{K}_{1}$ to the $\mathrm{P}_{1}$ tide, as the $\mathrm{K}_{1}$ tide has a period rather close to $\mathrm{P}_{1}\left(23.93 \mathrm{~h}\right.$ of $\mathrm{K}_{1}$ versus $24.07 \mathrm{~h}$ of $\left.\mathrm{P}_{1}\right)$.

The simulations in time shift (Fig. 8) resulted in a somewhat different behaviour of the harmonic constituents, namely, the $\mathrm{M}_{2}$ and $\mathrm{S}_{2}$ tides (which have large amplitudes) behave similarly as in the time drift simulations, whereas the $\mathrm{K}_{2}$ and $\mathrm{N}_{2}$ tides have larger amplitudes when the drift is negative, and smaller ones when the drift is positive. In particularly, $\mathrm{N}_{2}$ values vary from $200 \%$ down to $10 \%$ of the nonshifted simulation, obviously due to the influence of a larger $\mathrm{M}_{2}$ tide. The drift of $\pm 120 \mathrm{~min}$ generates the decrease in the $M_{2}$ and $S_{2}$ tides for about $10 \%\left(8 \mathrm{~mm}\right.$ for $M_{2}, 5 \mathrm{~mm}$ for $\left.\mathrm{S}_{2}\right)$, whereas the of that drift $( \pm 60 \mathrm{~min})$ results in decrease of about $3-4 \%$ (2-3 $\mathrm{mm}$ for $\mathrm{M}_{2}, 2 \mathrm{~mm}$ for $\left.\mathrm{S}_{2}\right)$. Diurnal tides are more stable again, changing their amplitudes up to $4 \%$ from the real (non-shifted) one $\left(3 \mathrm{~mm}\right.$ for $\left.\mathrm{K}_{1}\right)$. 

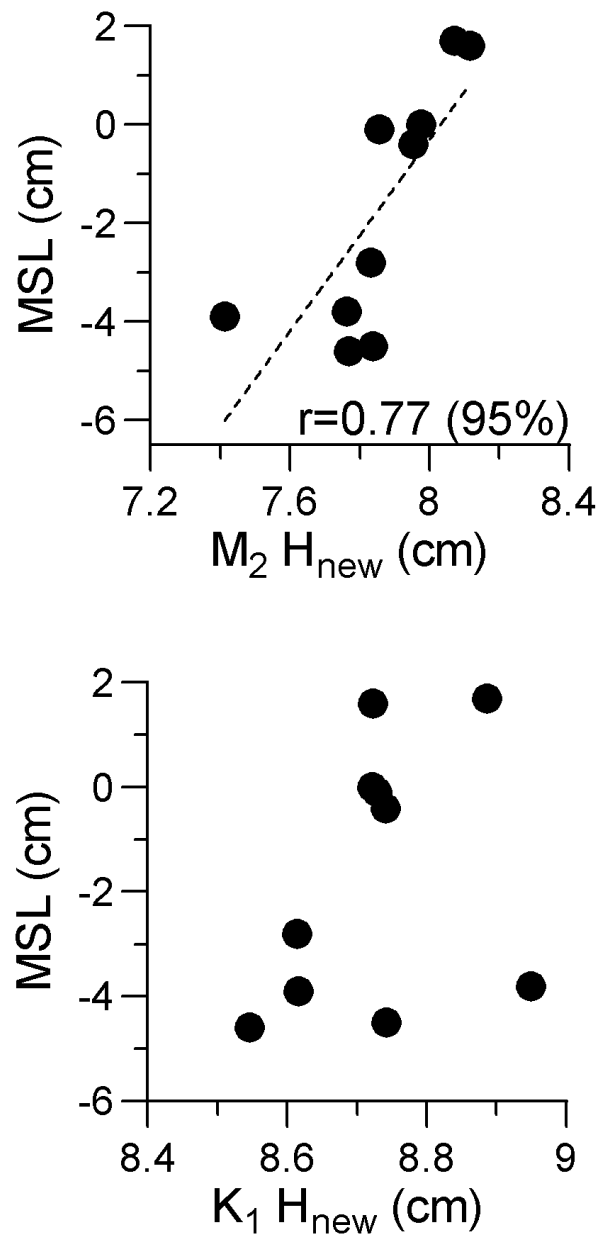

Fig. 5. Regression diagrams between MSL and the $M_{2}$ and $K_{1}$ amplitudes $\left(\mathrm{H}_{\text {new }}\right)$ obtained by the AutoCAD software between 1986 and 1995.

All of these simulations result in increased "false" energy in the domain of tidal frequencies (Fig. 9). False energies are larger for semidiurnal tides, in accordance with the changes in phases and amplitudes calculated from the real sea level data. They are also larger for time shift errors rather than time drift, due to the cumulative error effect in a month. The period of false maximums don't coincide with the tidal periods for the regular simulations (time drift and shift rate are constant). Nevertheless, the tidal energy is not recognized by the harmonic analysis in the case of the variable (random) rates, both in time drifts and shifts (Fig. 9c), and the remaining residual sea level series has a maximum exactly on the tidal periods (12.42 $-\mathrm{M}_{2}$ tide, $23.83-\mathrm{K}_{1}$ tide). This "false" energy, generated by the measuring and digitising errors, seems to be persistent in a number of sea level studies (e.g. Cerovečki et al., 1997; Raicich et al., 1999; Pasarić and Orlić, 2001; Vilibić, 2006), although it has been assumed there that a nonlinear coupling between the internal and surface tides and seiches might be responsible. However, this coupling has not been captured or modelled yet, leading to the conclusion that: (i) it is very weak or absent, and the residual energy at the $M_{2}$ and $K_{1}$ periods is a product of drifting and shifting errors in the sea level series, or (ii) it may be strong and dominant, but a part of the energy at these periods is surely the result of the errors in the sea level series.

\section{Conclusions}

The knowledge of harmonic constituents is essential when making tidal forecasts, as the rate of sea level changes serves as input in various activities dealing with the sea and coastal infrastructure (Vilibić et al., 2000). For example, sea level data is used within the various hydrotechnical projects, on offshore drilling platforms, in the charting and navigation safety studies, when building coastal infrastructure, etc. Therefore, determination of the tidal signal and the calculation of the harmonic constituents at one long-term station has been performed in this work, and the interannual variability is detected and discussed in the light of (i) measurement errors (clock errors, chart stretching due to changes in temperature and humidity, etc.), (ii) various digitising software packages that were changed over the period of operation (old VAX-based software versus new AutoCAD-based software), and (iii) natural changes induced by changes in MSL and bathymetry (dredging, etc.). A few conclusions may be extracted from the analyses in this paper:

- Semidiurnal tides possess larger variance than diurnal ones, being more prone to artificial errors in the sea level series. In addition, artificial errors usually decrease the amplitudes of a tide, as some of the tidal energy is transferred to the residual (de-tided) sea level series.

- Most of the observed changes in tidal amplitudes and phases come from artificially generated errors in the data, although some weak correlation is computed between some tidal amplitudes and the MSL (e.g. for the $\mathrm{M}_{2}$ tide). Based on that correlation (Fig. 5), an increase of $3 \mathrm{~cm}$ in the $\mathrm{M}_{2}$ amplitude may be expected for the MSL rise of $50 \mathrm{~cm}$, however, a numerical model should be applied in order to properly quantify this. Therefore, MSL variations have an effect on tides, but they can be hardly resolved from the data due to artificial errors. Other natural effects (e.g. dredging, building of piers, etc.) have a negligible effect on the tides, as these activities were not documented to occur in the wider region during the tide gauge operation.

- The upgrade of the digitising software decreased the errors being generated through the digitising process and increased the quality of the sea level data; however, some errors still remained in the series, mostly including the errors created during the measurements (clock and pen positioning, chart stretching). 

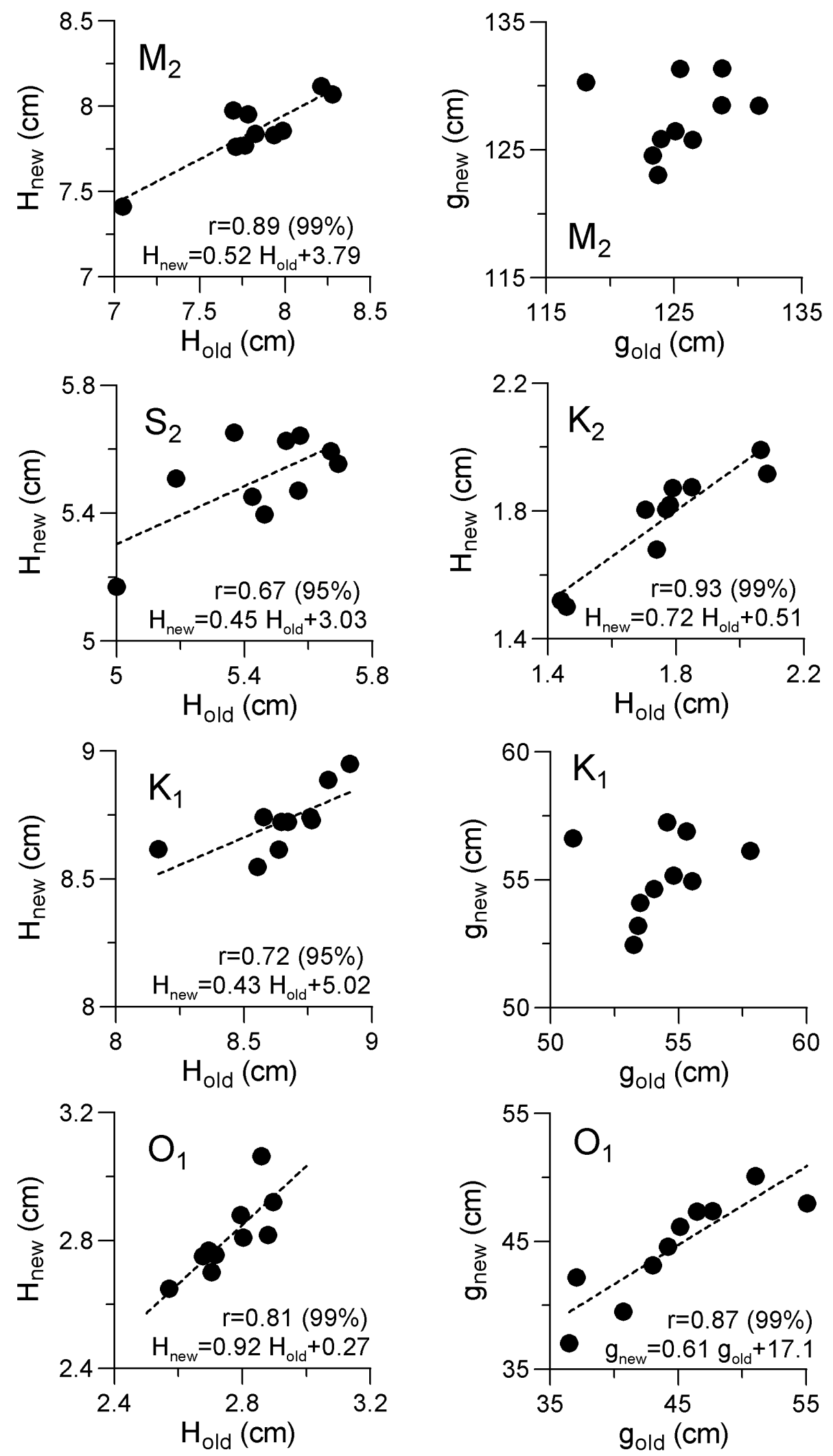

Fig. 6. Regression diagrams between the VAX-computed $\left(\mathrm{H}_{\mathrm{old}}, \mathrm{g}_{\text {old }}\right)$ and AutoCAD-computed $\left(\mathrm{H}_{\text {new }}\right.$, gnew $)$ amplitudes and phases between 1986 and 1995. 

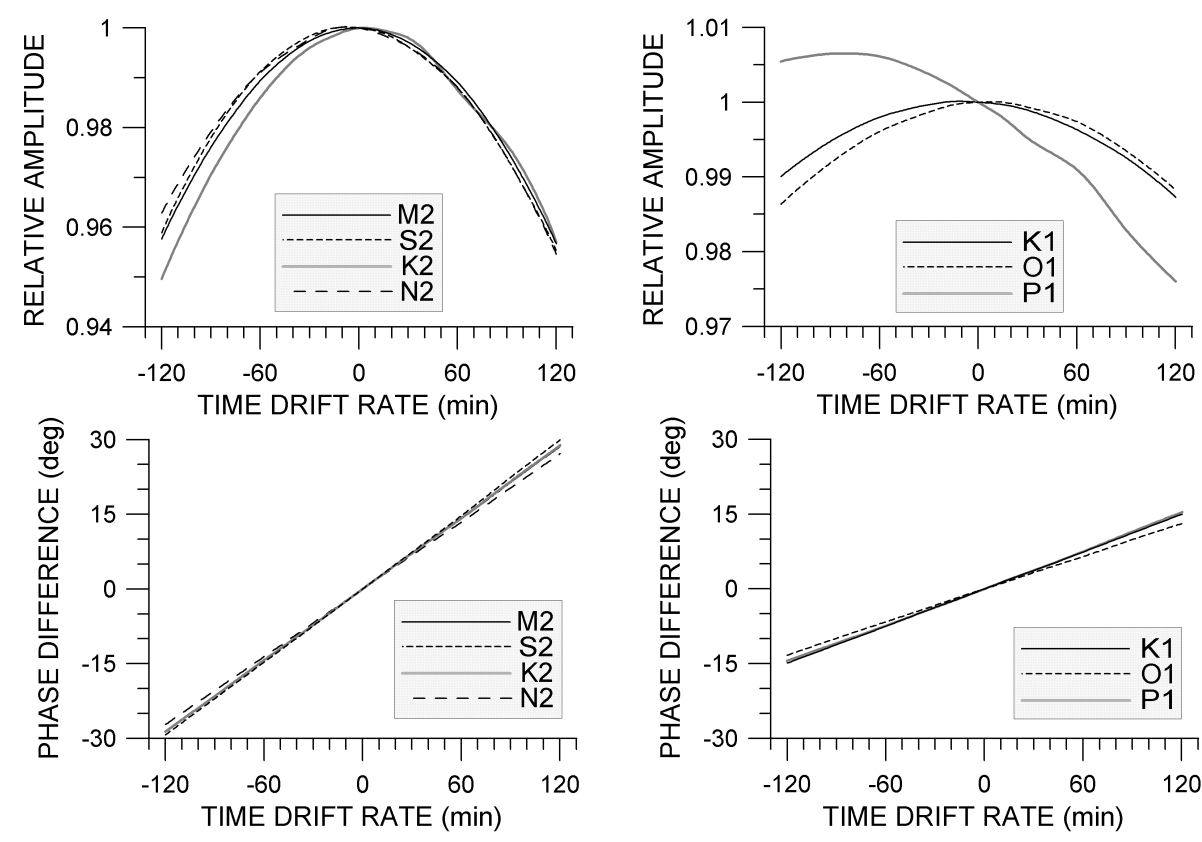

Fig. 7. Simulated changes in relative amplitudes and phase differences versus the time drift rate. The respective amplitude and phase are supposed to be 1 and 0 when no time drift was simulated.
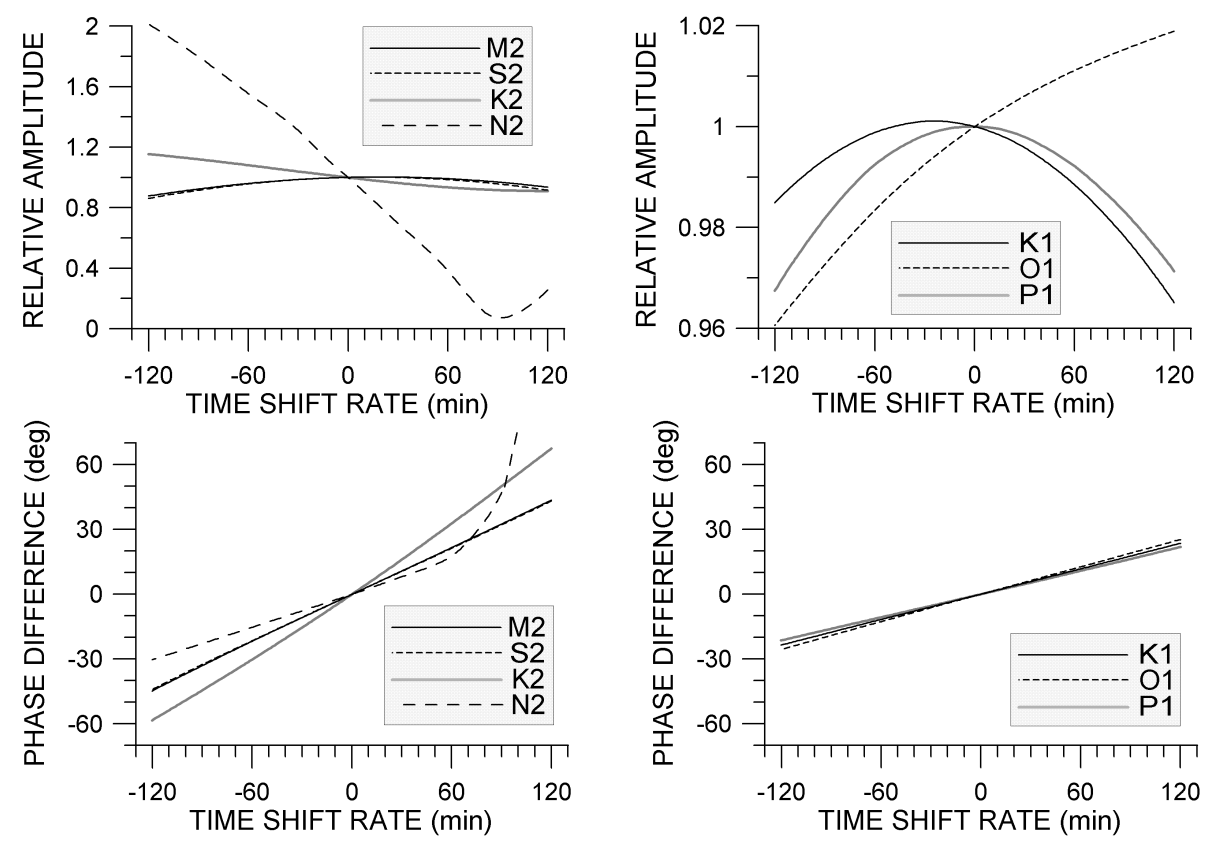

Fig. 8. Simulated changes in relative amplitudes and phase differences versus the time shift rate. The respective amplitude and phase are supposed to be 1 and 0 when no time shift was simulated.

- The errors that were created by artificial drifting and/or shifting of a chart in time may result in "false" residual energy on tidal frequencies. In particular, artificial energy at the $\mathrm{M}_{2}$ period (12.4 $\mathrm{h}$ ) has been documented in a large number of previous sea level studies, hypothesised to be a result of the nonlinear effects between tides, internal tides and seiches. However, the energy may be the result of drifting and shifting errors in sea the level series rather than of natural origin, which should be checked in the future through modelling studies. 

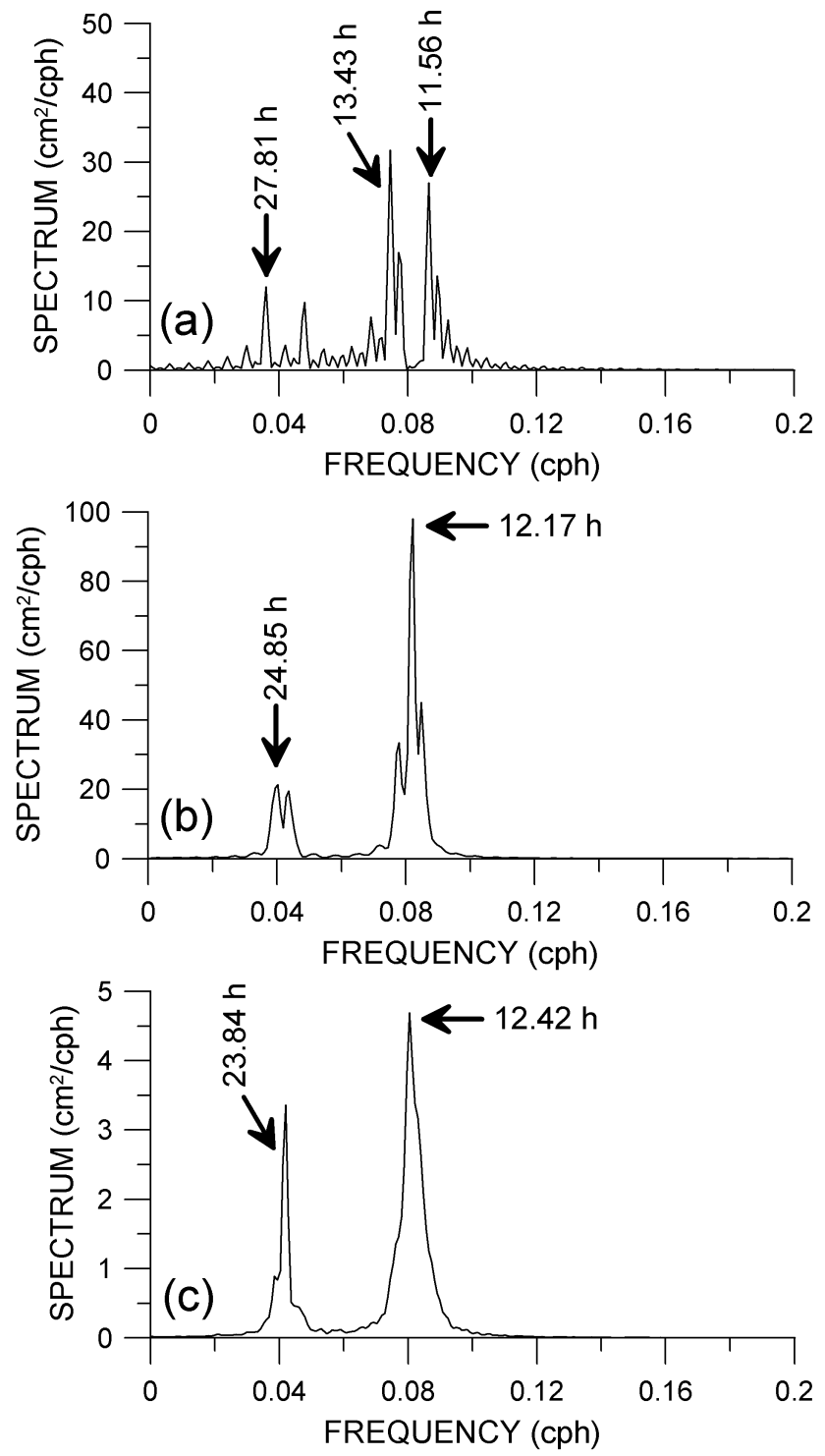

Fig. 9. Spectrum of the annual residual series computed from the simulated sea level series with (a) a time drift of $30 \mathrm{~min}$, (b) a time shift of $30 \mathrm{~min}$, and (c) a time drift randomly chosen for each artificial chart (week) with values between -120 and 120 min.

\section{References}

Bell, C., Vassie, J. M., and Woodworth, P. L.: POL/PSMSL Tidal Analysis Software Kit 2000 (TASK-2000), Permanent Service for Mean Sea Level, CCMS Proudman Oceanographic Laboratory, Bidston, 21 pp, 2000.

Cerovečki, I., Orlić, M., and Hendershott, M. C.: Adriatic seiche decay and energy loss to the Mediterranean, Deep-Sea Research I, 44, 2007-2029, 1997.

Chapalain, G. and Thais, L.: Tide, turbulence and suspended sediment modelling in the eastern English Channel, Coastal Engineering, 41, 295-316, 2000.

Kasumović, M.: Harmonic analysis of tides at Bakar (in Croatian), Geofizièki institut Prirodoslovno-matematièkog fakulteta Sveučilišta u Zagrebu, Radovi III/1, Zagreb, 1-9, 1952.

Lane, A: Bathymetric evolution of the Mersey Estuary, UK, 19061997: causes and effects, Estuarine Coastal and Shelf Sciences, 59, 249-263, 2004.

Pasarić, M. and Orlić, M.: Long-term meteorological preconditioning of the North Adriatic coastal floods, Continental Shelf Research, 21, 263-278, 2001.

Polli, S.: Le propagazione delle maree nell' Adriatico (in Italian), Atti del IX Convegno dell’ Associazione Geofisica Italiana, Roma, 1-11, 1960.

Prandle, D.: Operational oceanography in coastal waters, Coastal Engineering, 41, 3-12, 2000.

Pugh, D. T.: Tides, Surges and Mean Sea Level, John Wiley, Chicester, 472 pp, 1987.

Raicich, F., Orlić, M., Vilibić, I., and Malačič, V.: A case study of the Adriatic seiches (December 1997), Il Nuovo Cimento C, 22, 715-726, 1999.

Robinson, A. R., Tomasin, A., and Artegiani, A.: Flooding of Venice - phenomenology and prediction of the Adriatic storm surge, Quart. J. Roy. Meteorol. Soc., 99, 686-692, 1972.

Shureman, P.: Manual of Harmonic Analysis and Prediction of Tides, US Department of Commerce, Special Publication No 98, Washington, 317 pp, 1941.

Šigud, J.: Tide tables, Adriatic Sea - east coast - 1974 (in Croatian), Hydrographic Institute, Split, 1973.

UNESCO: Manual on sea level measurement and interpretation, Volume I - Basic procedures, IOC Manuals and Guides 14, UNESCO, 83 pp, 1985.

Vilibic̀, I.: The role of the fundamental seiche in the Adriatic coastal floods, Continental Shelf Research, 26, 206-216, 2006.

Vilibic̀, I., Leder, N., and Smirčič, A.: Storm surges in the Adriatic Sea: an impact on the coastal infrastructure, Periodicum Biologorum, 102, Supplement 1, 483-488, 2000.
Acknowledgements. A part of sea level charts has been digitised within ESEAS-RI project (EU funded project EVR1-CT-200240025). Half-century maintenance of the Split tide gauge carried out by personnel of Hydrographic Institute of the Republic of Croatia is particularly appreciated. The Permanent Service for Mean Sea Level kindly provided TASK software package, S. Čupić did quite great job with digitising of sea level charts, while M. Srdelić developed PC-based digitising software.

Topical Editor N. Pinardi thanks a referee for his help in evaluating this paper. 